This document is the accepted manuscript version of the following article:

Petrov, A. W., Ferri, D., Tarik, M., Kröcher, O., \& van Bokhoven, J. A. (2017). Deactivation Aspects of Methane Oxidation Catalysts Based on Palladium and ZSM-5. Topics in Catalysis, 60(1-2), 123-130. https://doi .org/10.1007/s11244-016-0724-6

\title{
Deactivation aspects of methane oxidation catalysts based on
}

\section{palladium and ZSM-5}

Andrey W. Petrov, ${ }^{1,2}$ Davide Ferri, ${ }^{1}$ Mohamed Tarik, ${ }^{1}$ Oliver Kröcher,,${ }^{1,3,}$ Jeroen A. van Bokhoven $1,2, *$

1 - Paul Scherrer Institut, CH-5232 Villigen PSI, Switzerland

2 - ETH Zurich, Institute for Chemical and Bioengineering, CH-8093 Zurich, Switzerland

3 - Ecole polytechnique fédérale de Lausanne (EPFL), Institute of Chemical Sciences and Engineering, CH-1015 Lausanne, Switzerland

* Corresponding author

oliver.kroecher@psi.ch

jeroen.vanbokhoven@,chem.ethz.ch
Tel. +41563102066 Fax +41563102199

Tel. $+41446325542 \quad$ Fax +41446321010 


\begin{abstract}
Catalytic methane oxidation is used in exhaust gas after treatment to reduce methane emissions in stationary combustion processes as well as in natural gas vehicles. $\mathrm{Pd} /$ zeolite catalysts provide higher activity than the commonly used $\mathrm{Pd} / \mathrm{Al}_{2} \mathrm{O}_{3}$, but suffer from rapid deactivation under reaction conditions and in the presence of steam. This work presents a detailed study of deactivation of 1 wt.\% Pd/H-ZSM-5 catalyst in reaction conditions in dry and wet feed including characterization of both the active phase and the support.

Initially well-dispersed $\mathrm{PdO}$ particles are not stable and sinter immediately after the exposure to the reaction mixture even in dry feed and stabilize at lower dispersion level. Despite the reasonable methane oxidation activity exhibited by the large particles, the initial PdO particles could potentially provide a $40{ }^{\circ} \mathrm{C}$ lower methane oxidation temperature. In the presence of water in the feed at moderate temperature $\left(450^{\circ} \mathrm{C}\right)$, support degradation governs the deactivation of the catalyst, which is evidenced by a significant decrease in BET surface area and generation of extra-framework aluminium species. These results suggest that active and stable catalysts could be obtained by careful choice and design of the support material with the aim to guarantee high dispersion of $\mathrm{PdO}$.
\end{abstract}

Keywords: methane oxidation, exhaust aftertreatment, palladium, zeolite, deactivation, ageing 


\section{Introduction}

Natural gas, which consists primarily of methane, is a promising midterm fuel to significantly reduce carbon dioxide emissions due to its advantageous hydrogen-to-carbon ratio, established usage applications, abundance, available world-wide reserves and distribution network, and the possibility to produce it from renewable sources (bio-gas). Lean-burn natural gas engines are very efficient and allow to significantly reduce $\mathrm{CO}_{2}, \mathrm{NO}_{\mathrm{x}}$ and $\mathrm{CO}$ emissions compared to gasoline and diesel engines. However, considerable amounts of methane remain unburnt especially under lean conditions and are emitted at concentrations of several thousand ppm. This causes environmental concerns as methane possesses about 20 times larger global warming potential than $\mathrm{CO}_{2}$. Hence, lean methane abatement requires an efficient and stable methane oxidation catalyst [1-5].

Several reports showed $\mathrm{Pd} /$ zeolite catalysts to be promising candidates to substitute conventional $\mathrm{Pd} / \mathrm{Al}_{2} \mathrm{O}_{3}$ catalysts due to their high activity and ability to convert methane at lower temperature [6-15]. ZSM-5 and mordenite are the most commonly studied zeolite frameworks [7,9-11]. From a comparison of methane oxidation on various zeolite-based catalysts over a broad range of palladium loadings (1.2 to $4 \mathrm{wt} . \% \mathrm{Pd}$ ) and $\mathrm{Si} / \mathrm{Al}$ ratios (7 to 27) it was concluded that the highest reaction rate is reached on the STI-type framework followed by MFI, BEA and MOR [13]. A study with low palladium loadings (0.1 to 0.3 wt. \%) indicated that high $\mathrm{Si} / \mathrm{Al}$ ratio is generally favorable to obtain more active and stable catalysts irrespective of the zeolite framework $[9,11,12]$. M'Ramadj et al. [8] compared the acidity of $\mathrm{Pd} / \mathrm{Al}_{2} \mathrm{O}_{3}$ and $\mathrm{Pd} / \mathrm{ZSM}-5$ prepared with different methods and concluded that strong Brönsted acidity was crucial for methane activation at low temperature. Among various preparation methods, ion-exchange of palladium ammine complex yielded higher palladium dispersion and initial activity [9]. 
Despite the significant number of studies on methane oxidation over Pd/zeolite catalysts, very limited structural data is available on their ageing behavior and the course of deactivation. Activity and resistance to deactivation in the presence of water are serious issues for zeolite catalysts for methane oxidation. Several authors $[9,14,16]$ performed stability tests on various catalysts, but characterization of the spent catalysts was not provided. Okumura et al. $[11,12]$ measured Pd K-edge EXAFS of ZSM-5 and mordenite supported palladium before and after reaction and concluded $\mathrm{PdO}$ sintering to be the reason for the observed deactivation. However, the structural properties of the corresponding supports were not provided, thus leaving the role of the support in the deactivation of the catalyst ambiguous. A comprehensive study of the deactivation process of catalysts based on palladium and zeolites comprising characterization of both the support and the active phase would be helpful for the design of an active and stable $\mathrm{Pd} /$ zeolite methane oxidation catalyst.

In this work, the evolution of the structure of Pd/ZSM-5 in the reaction conditions, including also the presence of steam in the feed, was investigated with a focus on both the metal active phase and the zeolite support using nitrogen adsorption, solid-state nuclear magnetic resonance, powder X-ray diffraction, transmission electron microscopy and X-ray absorption spectroscopy.

\section{Experimental}

\subsection{Catalyst synthesis}

ZSM-5 zeolite in Na-form with $\mathrm{Si} / \mathrm{Al}=20$ (Zeocat PZ-2/40) was kindly supplied by Zeochem. The zeolite was calcined at $600{ }^{\circ} \mathrm{C}$ prior to the catalyst synthesis. The calcined zeolite $(4 \mathrm{~g})$ was ion-exchanged three times with $\mathrm{NH}_{4} \mathrm{NO}_{3}(1 \mathrm{M}, 20 \mathrm{ml})$ and calcined at $600{ }^{\circ} \mathrm{C}$ to obtain

the H-form. H-ZSM-5 was then ion-exchanged at room temperature for $24 \mathrm{~h}$ with the required amount of $\left[\mathrm{Pd}\left(\mathrm{NH}_{3}\right)_{4}\right]\left(\mathrm{NO}_{3}\right)_{2}$ solution $(\mathrm{pH}=9)$ to obtain 1 wt. \% loading of 
palladium. After drying at $120{ }^{\circ} \mathrm{C}$ for $12 \mathrm{~h}$, the $\mathrm{Pd} / \mathrm{H}-\mathrm{ZSM}-5$ catalyst was obtained by calcination at $500{ }^{\circ} \mathrm{C}$ for $2 \mathrm{~h}$. This sample was labelled as "calcined". The heating rate was set to $2{ }^{\circ} \mathrm{C} / \mathrm{min}$ to obtain highly dispersed $\mathrm{PdO}$ nanoparticles [17-19].

\subsection{Catalyst activity evaluation}

Evaluation of the catalytic activity and stability was carried out using the catalyst in powder form in a dedicated setup comprising a quartz-glass plug flow reactor (ID $=6 \mathrm{~mm}$ ), gas flowmeters, heating control and a gas analysis system (InProcess Instruments GAM 400 mass spectrometer). Fragments with the m/z ratio of $2\left(\mathrm{H}_{2}\right), 12(\mathrm{C}), 15\left(\mathrm{CH}_{4}\right), 16\left(\mathrm{O}_{2}\right), 18\left(\mathrm{H}_{2} \mathrm{O}\right)$, $28\left(\mathrm{~N}_{2}\right), 30(\mathrm{NO}), 32\left(\mathrm{O}_{2}\right)$ and $44\left(\mathrm{CO}_{2}\right)$ were followed. The catalyst $(50 \mathrm{mg}, 150-200 \mu \mathrm{m}$ sieve fraction) was mixed with cordierite $(150 \mathrm{mg}, 100-150 \mu \mathrm{m})$ to mitigate the exothermic effect of the reaction and was then fixed firmly in the reactor between two quartz wool plugs. Methane conversion curves were taken at the heating/cooling rate of 10,20 and $50{ }^{\circ} \mathrm{C} / \mathrm{min}$ in the feed comprising 1 vol. $\% \mathrm{CH}_{4}, 4$ vol. $\% \mathrm{O}_{2}, \mathrm{~N}_{2}$ balance (GHSV $=80$ '000 h $\mathrm{h}^{-1}$ ). The first ascending ramp was taken from $200{ }^{\circ} \mathrm{C}$ to $550{ }^{\circ} \mathrm{C}$, followed by stabilization of the catalyst at $550{ }^{\circ} \mathrm{C}$ for $30 \mathrm{~min}$. Then, the reactor was cooled to $300{ }^{\circ} \mathrm{C}$ and the heating/cooling sequence to $550{ }^{\circ} \mathrm{C}$ was repeated twice without waiting at $550{ }^{\circ} \mathrm{C}$ to ensure that the catalyst had stabilized and the data obtained was reproducible. After this treatment, the catalyst was labelled as "stabilized catalyst". Isothermal activity tests were performed upon introduction of the reaction feed at 325,360 or $390{ }^{\circ} \mathrm{C}$ without pre-treatment. Hydrothermal stability was tested at constant temperature $\left(450{ }^{\circ} \mathrm{C}\right)$ with the addition of 5 vol. $\%$ of steam to the feed. Alternately, steam was added to and removed from the feed at intervals of $60 \mathrm{~min}$ at the same temperature in a separate experiment. No other products than $\mathrm{CO}_{2}$ and $\mathrm{H}_{2} \mathrm{O}$ were detected during all activity tests. 


\subsection{Catalyst characterization}

The palladium loading as well as the $\mathrm{Si}: \mathrm{Al}: \mathrm{Na}$ ratio of the starting material and the final catalyst were determined by inductively coupled plasma mass spectrometry (ICP-MS) using an Agilent 7700x ICPMS instrument after complete digestion of the samples in the $\mathrm{HCl} / \mathrm{HNO}_{3} / \mathrm{HF}$ mixture (ratio 6:3:1) in a 3000 Anton Paar microwave digestion unit. The zeolite crystallinity and the presence of the PdO phase were confirmed by powder X-ray diffraction (XRD) using a Bruker D8 Advance AXS diffractometer with $\mathrm{Cu} \mathrm{K} \alpha$ radiation in the $2 \theta$ range from $10^{\circ}$ to $60^{\circ}$. Scanning transmission electron microscopy (STEM) images were taken with a Hitachi HD-2700 microscope at the $200 \mathrm{kV}$ acceleration voltage. Extended X-ray adsorption fine structure (EXAFS) data were measured at the Pd K-edge (24.35 keV) in transmission mode on pelletized samples at the SuperXAS beamline of the Swiss Light Source (SLS, Paul Scherrer Institut). The Fourier transformation of the $\mathrm{k}^{2}$-weighted EXAFS functions was performed the range $3-12 \AA^{-1}$ [20]. Data reduction was performed using the Athena software package [21]. Solid-state magic angle spinning nuclear magnetic resonance (MAS NMR) ${ }^{27} \mathrm{Al}$ spectra were recorded at $10 \mathrm{kHz}$ collecting 2048 accumulations on a Bruker Avance $400 \mathrm{MHz}$ spectrometer with ammonium aluminium sulfate dodecahydrate $\left(\mathrm{AlNH}_{4}\left(\mathrm{SO}_{4}\right)_{2} \cdot 12 \mathrm{H}_{2} \mathrm{O}\right)$ as reference. The textural properties of the support were obtained from nitrogen physisorption measurements at $77 \mathrm{~K}$ using a Quantachrome Autosorb 1 instrument. Prior to the measurement the samples were degassed for $6 \mathrm{~h}$ at $200^{\circ} \mathrm{C}$ to remove water and other adsorbed species. The specific surface area was calculated using the Brunauer-Emmett-Teller (BET) method. The micropore volume and micropore surface area were calculated from the t-plot.

\section{Results and discussion}

\subsection{Catalyst stabilization}


Table 1 shows the chemical composition of the support and the final catalyst determined by ICP-MS. The Si/Al ratio was found to be 20.2 which is in accordance with the supplier specifications. The $\mathrm{Na} / \mathrm{Al}$ ratio in the original zeolite was much lower than 1 , indicating that the zeolite was initially in the mixed $\mathrm{Na}-\mathrm{H}$ form. The decrease in $\mathrm{Na} / \mathrm{Al}$ ratio from 0.22 to 0.07 confirmed that most of the sodium was removed from the final catalyst by the repeated exchange with ammonium nitrate followed by calcination. The palladium loading was 0.88 wt. \%, which was slightly lower than the expected value.

Figure 1 shows methane oxidation profiles of the $\mathrm{Pd} / \mathrm{H}-\mathrm{ZSM}-5$ catalyst obtained during the first ascending ramp at the three different heating rates $\left(10,20\right.$ and $\left.50{ }^{\circ} \mathrm{C} / \mathrm{min}\right)$. The observed conversion gradually increased with the increasing heating rate in the region between 250 and $450{ }^{\circ} \mathrm{C}$ and remained almost identical above $450{ }^{\circ} \mathrm{C}$ for the three ramp rates. After operation at $550{ }^{\circ} \mathrm{C}$ for $30 \mathrm{~min}$ and subsequent repetition of the heating/cooling sequence, the methane oxidation profile of the stabilized catalyst exhibited lower activity below $375{ }^{\circ} \mathrm{C}$ than that obtained in the ascending ramps for the different heating rates. Above ca. $375^{\circ} \mathrm{C}$, the activity was slightly better.

When methane was introduced to the feed at the temperature higher than $200{ }^{\circ} \mathrm{C}$, i.e. at 325 , 360 and $390{ }^{\circ} \mathrm{C}$ (filled symbols in Figure 1), the initial conversion was significantly higher than that of the stabilized catalyst. However, the activity returned to the value measured for the stabilized catalyst within the 30 min of isothermal operation at those temperatures.

The excess amount of methane converted during the first ascending ramp compared to the following runs between $250{ }^{\circ} \mathrm{C}$ and $450{ }^{\circ} \mathrm{C}$ (about $2 \mathrm{mmol}$ ) was significantly larger than the amount of palladium in the catalyst bed $(0.072 \mathrm{mmol})$ while no other reaction products were detected. This indicates that the higher conversion observed in the first run and in the subsequent isothermal runs is catalytic and occurred neither due to a stoichiometric reaction nor to precursor decomposition. Such behavior suggests that the calcined catalyst was 
initially very active, but then changed rapidly and irreversibly in the reaction environment. It is likely that the activity changes originate from modification of the structure of the active phase and/or of the zeolite support.

Therefore, the calcined catalyst and the catalyst obtained at $360{ }^{\circ} \mathrm{C}$ after the $30 \mathrm{~min}$ run were characterized by scanning transmission electron microscopy (STEM, Figure 2). A slow calcination program should ensure that the palladium objects remain well dispersed on the zeolite support [17-19]. In fact, the calcined Pd/H-ZSM-5 exhibited well-dispersed palladium nanoparticles of 1-2 $\mathrm{nm}$ diameter (Figure 2a). Although this is larger than the ZSM-5 micropore diameter of $0.55 \mathrm{~nm}$, such particles are likely located within the zeolite structure [22]. The image of the catalyst obtained after contact with the feed at $360^{\circ} \mathrm{C}$ shows that these particles already aggregated achieving a final size between 5 and $10 \mathrm{~nm}$ (Figure 2b). We speculate that the aggregation was induced by the presence of methane, since the particles of 1-2 $\mathrm{nm}$ are the result of calcination in air at higher temperature. The rather irregular morphology of the large objects observed after reaction together with the ramification of many particles encourage to think that particle growth derives from the high mobility of the small palladium particles on the support. The significant change in dispersion was also observed by X-ray diffraction (XRD, Figure 3). The reflection at $2 \theta=33.8^{\circ}$ attributed to the $\mathrm{PdO}$ phase [23-25] was not detected in the pattern of the calcined catalyst thus confirming its high metal dispersion, but it appeared in the spent catalyst. Figure 4 shows the Fourier transform of the palladium K-edge EXAFS spectrum of the calcined sample. Besides the first Pd-O coordination shell (ca. $1.5 \AA$ ), a less intense contribution from the Pd-O-Pd shell (ca. 3 $\AA$ ) than in the $\mathrm{PdO}$ reference was also present, which suggests that palladium was in the oxidized state in the calcined catalyst. Although no metallic palladium species were detected by XRD and EXAFS, the question whether the initial PdO particles undergo some extent of reduction during the sintering process under these conditions will need to be answered by in 
situ observation of the palladium oxidation state [26,27], which is beyond the scope of this work. Figure 3 also demonstrates that the reflections corresponding to ZSM-5 did not change indicating that the zeolite crystal structure remained intact during the experiment.

Figure 5 shows ${ }^{27} \mathrm{Al}$ MAS NMR spectra of Na-ZSM-5, calcined Pd/H-ZSM-5 and the spent catalyst operated at $360{ }^{\circ} \mathrm{C}$ for $30 \mathrm{~min}$. Two distinct peaks were observed at around 0 and 55 ppm chemical shift. The latter signal corresponds to the tetrahedral framework aluminium $\left(\mathrm{Al}_{\mathrm{T}}\right)$ while the former to the framework-associated octahedral aluminium ( $\left.\mathrm{Al}_{\text {oct }}\right)$. Additionally, framework aluminium distortions are typically recognized from the broadening and shift to lower values of the $\mathrm{Al}_{\mathrm{T}}$ feature that produces an asymmetric peak $[25,28]$. Compared to the Na-ZSM-5 material the calcined and spent Pd/H-ZSM-5 catalysts exhibited a slight increase in the framework aluminium distortion and the corresponding $\mathrm{Al}_{\mathrm{T}}$ peak shifted from $54.3 \mathrm{ppm}$ to $53.8 \mathrm{ppm}$ and $53.7 \mathrm{ppm}$, respectively.

Textural properties of the parent Na-ZSM-5, calcined Pd/H-ZSM-5 and spent Pd/H-ZSM-5 obtained from nitrogen physisorption are given in Table 2. Specific surface area and micropore volume of the spent catalyst slightly decreased compared to the calcined catalyst indicating that the zeolite structure was not affected by exposure to the reaction mixture. PdO particle sintering observed by STEM and XRD together with only minor changes in the support material detected by ${ }^{27} \mathrm{Al}$ MAS NMR and nitrogen physisorption indicate that the support was stable under reaction conditions. Therefore, we consider that the loss of initial activity was induced solely by $\mathrm{PdO}$ nanocluster sintering.

Despite its initial deactivation, Pd/H-ZSM-5 was still very active in methane oxidation, exhibiting 50\% methane conversion $\left(\mathrm{T}_{50}\right)$ below $400{ }^{\circ} \mathrm{C}$. However, if the $\mathrm{PdO}$ nanoparticles would remain at the dispersion level of the calcined Pd/H-ZSM-5 catalyst, the activity would be even higher, as it is suggested by the dotted line in Figure 1. This curve is the methane oxidation profile obtained by joining the first points of the isothermal experiments (Figure 1, 
black arrows). Such a catalyst would provide a shift of $\mathrm{T}_{50}$ by about $40{ }^{\circ} \mathrm{C}$ to lower values compared to the stabilized one.

\subsection{Ageing in the presence of steam}

It is well-known that steam has a detrimental effect on the activity of $\mathrm{Pd} /$ zeolite catalysts significantly decreasing their lifetime $[10,12,13]$. To study catalyst degradation over time, $\mathrm{Pd} / \mathrm{H}-\mathrm{ZSM}-5$ was exposed to the reaction mixture with the addition 5 vol. $\%$ of steam at 450 ${ }^{\circ} \mathrm{C}$ for $1,4,8$ and $16 \mathrm{~h}$ and was then characterized by STEM, nitrogen physisorption, ${ }^{27} \mathrm{Al}$ MAS NMR spectroscopy and XRD. To compare the deactivation rate in dry and wet feed, a test with repeated addition and removal of 5 vol. $\%$ of steam was also performed. Figure 6 depicts the activity decrease of Pd/H-ZSM-5 for methane oxidation under these conditions. In the case of the constant wet feed, rapid deactivation of the catalyst occurred immediately after water was added, resulting in loss of two thirds of the initial activity in the first 4 hours. The rapid deactivation phase was followed by a slower phase where the conversion dropped from 25 to $10 \%$ in 12 hours. Methane conversion followed the same trend for all samples thus showing good reproducibility of the ageing experiments. When steam was repeatedly added to and removed from the feed every $60 \mathrm{~min}$, the deactivation rate in the wet feed segment was similar to that in the constant wet feed mode, but the overall deactivation rate of the catalyst over time on stream slowed down. Upon the addition of steam an instant loss of methane conversion occurred, which confirms the sensitivity of the Pd/H-ZSM-5 system to water. Activity also recovered very quickly when steam was removed from the feed and no loss of activity was observed in the dry feed segment. However, methane conversion never returned to the level of the previous segment in dry feed, suggesting irreversible deactivation of the catalyst. 
XRD patterns of the calcined catalyst and of that aged in the presence of steam are presented in Figure 7. No significant difference in the intensity of peaks corresponding to ZSM-5 was observed confirming that the support remained crystalline after ageing. The PdO phase $(2 \theta=$ $33.8^{\circ}$ ), which could not be detected in the calcined catalyst due to its high dispersion (Figure 3b), appeared in the diffractograms of all samples exposed to steam showing sintering of the PdO nanoparticles.

Despite the absence of significant changes in the diffraction patterns of the support, the textural properties experienced measurable variations. Table 3 shows the results of nitrogen physisorption experiments. Both the specific surface area and the micropore volume of $\mathrm{Pd} / \mathrm{H}-$ ZSM-5 decreased with increasing ageing time, thus revealing the gradual degradation of the zeolite pore structure.

Figures 3 and 5 illustrate the superior sensitivity of NMR spectroscopy to structural changes of the zeolite framework compared to XRD and it was thus exploited to characterize the aged samples. Figure 8 shows ${ }^{27}$ Al MAS NMR spectra of calcined and aged catalysts. The Al oct signal $(0 \mathrm{ppm})$ only slightly increased with increasing ageing time. More pronounced changes were observed for the $\mathrm{Al}_{\mathrm{T}}$ signal, which gradually shifted from $53.8 \mathrm{ppm}$ for the calcined catalyst to $52.2 \mathrm{ppm}$ for the sample aged for 16 hours. The peak broadening observed in the region from 50 to $20 \mathrm{ppm}$ indicated the relative increase in the amount of distorted aluminium species $[25,28]$, thus demonstrating the framework degradation that could not be observed by XRD. The data provided evidence of significant degradation of the zeolite framework under reaction conditions in wet feed at mild temperatures, which is known to severely limit the temperature range of application of zeolite-based catalysts.

STEM images of the sample aged for $16 \mathrm{~h}$ further confirmed the data obtained by XRD, NMR and nitrogen physisorption measurements. Figures 9(a) and 9(b) show large and irregular PdO nanoparticles with sizes ranging from tens to hundreds of nm. PdO particle size 
distribution statistics shown in Figure 9(c) suggest that the addition of steam to the feed lead to the formation of even larger PdO particles than in dry feed, which was likely accelerated by the zeolite degradation.

\section{Conclusions}

Deactivation of $\mathrm{Pd} / \mathrm{H}-\mathrm{ZSM}-5$ in methane oxidation was studied by characterizing both the active phase and the zeolite support. ZSM-5 zeolite with $\mathrm{Si} / \mathrm{Al}$ ratio 20 is unable to stabilize

one to two nanometer $\mathrm{PdO}$ nanoparticles upon exposure to the reaction mixture. As a consequence, the metal sinters to 5 to $10 \mathrm{~nm}$ nanoparticles, which are then active and stable in dry reaction conditions. The zeolite support remains stable during this process. The initial highly dispersed $\mathrm{PdO}$ nanoparticles of the calcined catalyst provide around $40{ }^{\circ} \mathrm{C}$ lower temperature of $50 \%$ methane oxidation compared to the stabilized catalyst. This implies that Pd/ZSM-5 has a great potential in methane oxidation, which could be realized by preserving the initial dispersion of the palladium active phase.

Ageing of the catalyst in a feed containing water reveals partial zeolite collapse. Although the long-range structure of the support was preserved, a significant loss of surface area and an increase in $\mathrm{Al}$ distortion were observed by nitrogen physisorption and ${ }^{27} \mathrm{Al}$ MAS NMR spectroscopy. The average PdO particle size was significantly larger than in the dry feed suggesting that support degradation contributes to the sintering of $\mathrm{PdO}$ particles in the wet feed. Hence, the zeolites that are more resistant to steaming are favored for the design of a hydrothermally stable methane oxidation catalyst.

\section{Acknowledgements}

The authors would like to thank the Paul Scherrer Institut for financial support and for granting access to SLS, Dr. F. Krumeich (ETH Zurich) for the electron microscopy images, 
Dr. R. Verel (ETH Zurich) for assistance with NMR measurements and Dr. M. Nachtegaal (PSI) for his support with XAS measurements. 


\section{References}

1. Choudhary TV, Banerjee S, Choudhary VR (2002) Catalysts for combustion of methane and lower alkanes. Appl Catal A: General 234:1-23

2. Gelin P, Primet M (2002) Complete oxidation of methane at low temperature over noble metal based catalysts: a review. Appl Catal B: Environmental 39:1-37

3. Gonzalez-Velasco JR, Botas JA, Gonzalez-Marcos JA, Gutierrez-Ortiz MA (1997) Influence of water and hydrocarbon processed in feedstream on the three-way behaviour of platinum-alumina catalysts. Appl Catal B: Environmental 12:61-79

4. Lampert JK, Kazi MS, Farrauto RJ (1997) Palladium catalyst performance for methane emissions abatement from lean burn natural gas vehicles. Appl Catal B: Environmental $14: 211-223$

5. Lee JH, Trimm DL (1995) Catalytic combustion of methane. Fuel Process Technol 42:339359

6. Kalantar Neyestanaki A, Kumar N, Lindfors LE (1995) Catalytic combustion of propane and natural gas over $\mathrm{Cu}$ and Pd modified ZSM zeolite catalysts. Appl Catal B: Environmental $7: 95-111$

7. Li Y, Armor JN (1994) Catalytic combustion of methane over palladium exchanged zeolites. Appl Catal B: Environmental 3:275-282

8. M'Ramadj O, Li D, Wang X, Zhang B, Lu G (2007) Role of acidity of catalysts on methane combustion over Pd/ZSM-5. Catal Commun 8:880-884

9. Maeda H, Kinoshita Y, Reddy KR, Muto K, Komai S, Katada N, Niwa M (1997) Activity

of palladium loaded on zeolites in the combustion of methane. Appl Catal A: General 163:5969

10. Montes de Correa C, Villa AL (1996) Combustion of methane over palladium ZSM-5 and mordenite catalysts. Appl Catal B: Environmental 10:313-323 
11. Okumura K, Matsumoto S, Nishiaki N, Niwa M (2003) Support effect of zeolite on methane combustion activity of palladium. Appl Catal B: Environmental 40:151-159

12. Okumura K, Shinohara E, Niwa M (2006) Pd loaded on high silica beta support active for the total oxidation of diluted methane in the presence of water vapor. Catal Today 117:577583

13. Park JH, Kim B, Shin CH, Seo G, Kim SH, Hong SB (2009) Methane combustion over Pd catalysts loaded on medium and large pore zeolites. Top Catal 52:27-34

14. Shi C, Yang L, Cai J (2006) Cerium promoted Pd/HZSM-5 catalyst for methane combustion. Fuel 86:106-112

15. Shi C, Yang L, Wang Z, He Z, He X, Cai J, Li G, Wang X (2003) Promotion effects of $\mathrm{ZrO}_{2}$ on the Pd/HZSM-5 catalyst for low-temperature catalytic combustion of methane. Appl Catal A: General 243:379-388

16. Zhang B, Wang X, M'Ramadj O, Li D, Zhang H, Lu G (2008) Effect of water on the performance of Pd-ZSM-5 catalysts for the combustion of methane. J Nat Gas Chem 17:8792

17. Homeyer ST, Sachtler WMH (1989) Elementary steps in the formation of highly dispersed palladium in NaY. J Catal 117:91-101

18. Zhang Z, Mestl G, Knözinger H, Sachtler WMH (1992) Effects of calcination program and rehydration on palladium dispersion in zeolites $\mathrm{NaY}$ and 5A. Appl Catal A: General $89: 155-168$

19. Pommier B, Gelin P (1999) On the nature of Pd species formed upon exchange of HZSM-5 with $\mathrm{Pd}\left(\mathrm{NH}_{3}\right) 4^{2+}$ and calcination in $\mathrm{O}_{2}$. Phys Chem Chem Phys 1:1665-1672

20. Lamberti C, van Bokhoven J (2016) X-Ray Absorption and Emission Spectroscopy for Catalysis. In: van Bokhoven J, Lamberti C (eds) X-ray Absorption and X-ray Emission Spectroscopy: Theory and Applications. John Wiley \& Sons 
21. Ravel B, Newville M (2005) ATHENA, ARTEMIS, HEPHAESTUS: data analysis for Xray absorption spectroscopy using IFEFFIT. Journal of Synchrotron Radiation 12 (4):537541. doi:10.1107/S0909049505012719

22. Zecevic J, van der Eerden MJ, Friedrich H, de Jongh PE, de Jong KP (2013) Heterogeneities of the Nanostructure of Platinum/Zeolite Y Catalysts Revealed by Electron Tomography. ACS Nano 7:3698-3705

23. Domingos D, Simplicio LMT, Estrela GS, dos Prazeres MAG, Brandao ST (2007) Catalytic combustion of methane over $\mathrm{PdO}-\mathrm{CeO}_{2} / \mathrm{Al}_{2} \mathrm{O}_{3}$ and $\mathrm{PdO}-\mathrm{CeO}_{2} / \mathrm{ZrO}_{2}$ catalysts. Stud Surf Sci Catal 167:7-12

24. Jablonska M, Krol A, Kukulska-Zajac E, Tarach K, Chmielarz L, Gora-Marek K (2014) Zeolite Y modified with palladium as effective catalyst for selective catalytic oxidation of ammonia to nitrogen. J Catal 316:36-46

25. Pinar AB, Verel R, Perez-Pariente J, van Bokhoven JA (2014) Direct evidence of the effect of synthesis conditions on aluminum siting in zeolite ferrierite: ${ }^{27} \mathrm{Al}$ MQ MAS NMR study. Micropor Mesopor Mat 193:111-114

26. Grunwaldt JD, van Vegten N, Baiker A (2007). Chem Commun:4635-4637

27. Matam SK, Aguirre MH, Weidenkaff A, Ferri D (2010) Revisiting the Problem of Active Sites for Methane Combustion on $\mathrm{Pd} / \mathrm{Al}_{2} \mathrm{O}_{3}$ by Operando XANES in a Lab-Scale Fixed-Bed Reactor. J Phys Chem C 114:9439-9443

28. Yan Z, Ma D, Zhuang J, Liu X, Han X, Bao X, Chang F, Xu L, Liu Z (2003) On the aciddealumination of USY zeolite: a solid state NMR investigation. J Mol Catal A-Chem 194:153-167 


\section{Figure captions}

Figure 1. Methane conversion profiles of Pd/HZSM-5 in the first ascending ramp at $10(\square)$, $20(\mathrm{O})$ and $50{ }^{\circ} \mathrm{C} / \mathrm{min}(\triangle)$ rate and in isothermal runs at 325,360 and $390{ }^{\circ} \mathrm{C}(\boldsymbol{O}$, and arrows). The continuous black curve corresponds to the activity obtained after operating the catalyst at $550{ }^{\circ} \mathrm{C}$ for 30 min followed by two subsequent heating/cooling ramps (stabilized catalyst). The dotted curve is used to guide the eyes.

Figure 2. STEM images of Pd/H-ZSM-5 (a) calcined and (b) after the 30 min run at $360{ }^{\circ} \mathrm{C}$.

Figure 3. XRD patterns of (a) Na-ZSM-5, (b) Pd/H-ZSM-5 calcined at $500{ }^{\circ} \mathrm{C}$ and (c) spent $\mathrm{Pd} / \mathrm{H}-\mathrm{ZSM}-5$ operated at $360^{\circ} \mathrm{C}$ for $30 \mathrm{~min}$. The patterns are offset for clarity. Inset: $2 \theta$ range $32-36^{\circ}$ for (b) and (c).

Figure 4. Fourier transforms of non-phase shifted $\mathrm{k}^{2}$-weighted Pd K-edge EXAFS spectra of calcined Pd/H-ZSM-5 and PdO reference.

Figure 5. ${ }^{27} \mathrm{Al}$ MAS NMR spectra of Na-ZSM-5, calcined Pd/H-ZSM-5 and spent Pd/HZSM-5 operated at $360{ }^{\circ} \mathrm{C}$ for $30 \mathrm{~min}$.

Figure 6. Time dependence of methane conversion on Pd/H-ZSM-5 at $450{ }^{\circ} \mathrm{C}$ with constant and periodic addition of steam to the feed. Feed composition: 1 vol. $\% \mathrm{CH}_{4}, 4$ vol. $\% \mathrm{O}_{2}, 0$ or 5 vol. $\% \mathrm{H}_{2} \mathrm{O}$, bal. $\mathrm{N}_{2}$. 
Figure 7. XRD patterns of Pd/H-ZSM-5: (a) calcined and aged in wet reaction feed at $450{ }^{\circ} \mathrm{C}$ for (b) 1 , (c) 4, (d) 8 and (e) 16 hours. Patterns are offset for clarity. Inset: $2 \theta$ range 32-36

Figure $8 .{ }^{27} \mathrm{Al}$ MAS NMR spectra of Pd/H-ZSM-5: (a) calcined and (b-e) aged at $450{ }^{\circ} \mathrm{C}$ for $1,4,8$ and 16 hours in wet reaction feed. The vertical line is used to guide the eyes. Spectra are offset for clarity.

Figure 9. $(\mathrm{a}, \mathrm{b}) \mathrm{STEM}$ images of Pd/H-ZSM-5 aged at $450{ }^{\circ} \mathrm{C}$ for $16 \mathrm{~h}$ in wet reaction feed and (c) PdO particle size distribution in Pd/H-ZSM-5: calcined, spent in dry feed at $360{ }^{\circ} \mathrm{C}$ for $30 \mathrm{~min}$ and aged in wet feed at $450{ }^{\circ} \mathrm{C}$ for $16 \mathrm{~h}$. The size distribution is the result of counting ca. 700,180 and 100 particles, respectively. 
Table 1. Chemical composition of Na-ZSM-5 and the calcined Pd/H-ZSM-5 catalyst determined by ICP-MS.

\begin{tabular}{ccccc}
\hline Sample & \multicolumn{2}{c}{ Na-ZSM-5 } & \multicolumn{2}{c}{ Pd/H-ZSM-5 } \\
\hline \multirow{2}{*}{ Element } & Conc. & RSD & Conc. & RSD \\
& $($ wt. $\%)$ & $(\%)$ & $($ wt. $\%)$ & $(\%)$ \\
\hline $\mathrm{Na}$ & 0.36 & 0.47 & 0.12 & 3.01 \\
$\mathrm{Al}$ & 1.89 & 0.42 & 1.88 & 0.82 \\
$\mathrm{Si}$ & 39.6 & 0.24 & 39.3 & 0.92 \\
$\mathrm{Pd}$ & 0.00 & $\mathrm{n} / \mathrm{a}$ & 0.88 & 0.97 \\
$\mathrm{Si} / \mathrm{Al}$ & 20.2 & & 20.1 & \\
$\mathrm{Na} / \mathrm{Al}$ & 0.22 & & 0.07 & \\
\hline
\end{tabular}


Table 2. Specific surface area and micropore volume of Na-ZSM-5, calcined Pd/H-ZSM-5 and spent $\mathrm{Pd} / \mathrm{H}-\mathrm{ZSM}-5$ operated at $360^{\circ} \mathrm{C}$ for $30 \mathrm{~min}$

\begin{tabular}{ccccc}
\hline Sample & $\begin{array}{c}\text { BET surface } \\
\text { area }\left(\mathbf{m}^{2} / \mathbf{g}\right)\end{array}$ & $\begin{array}{c}\text { Micropore surface } \\
\text { area }\left(\mathbf{m}^{2} / \mathbf{g}\right)\end{array}$ & $\begin{array}{c}\text { External surface } \\
\text { area }\left(\mathbf{m}^{2} / \mathbf{g}\right)\end{array}$ & $\begin{array}{c}\text { Micropore } \\
\text { volume }\left(\mathbf{c m}^{\mathbf{3}} / \mathbf{g}\right)\end{array}$ \\
\hline Na-ZSM-5 & 533 & 287 & 246 & 0.119 \\
Pd/H-ZSM-5 & 507 & 275 & 232 & 0.115 \\
spent Pd/H-ZSM-5 & 494 & 265 & 229 & 0.109 \\
\hline
\end{tabular}


Table 3. BET specific surface area and total pore volume of calcined and aged Pd/H-ZSM-5.

\begin{tabular}{ccccc}
\hline $\begin{array}{c}\text { Ageing time } \\
(\mathbf{h})\end{array}$ & $\begin{array}{c}\text { BET surface } \\
\text { area }\left(\mathbf{m}^{\mathbf{2}} / \mathbf{g}\right)\end{array}$ & $\begin{array}{c}\text { Micropore surface } \\
\text { area }\left(\mathbf{m}^{\mathbf{2}} / \mathbf{g}\right)\end{array}$ & $\begin{array}{c}\text { External surface } \\
\text { area }\left(\mathbf{m}^{2} / \mathbf{g}\right)\end{array}$ & $\begin{array}{c}\text { Micropore } \\
\text { volume }\left(\mathbf{c m}^{\mathbf{3}} / \mathbf{g}\right)\end{array}$ \\
\hline 0 & 507 & 275 & 232 & 0.115 \\
1 & 481 & 256 & 225 & 0.107 \\
4 & 420 & 239 & 181 & 0.099 \\
8 & 382 & 218 & 164 & 0.090 \\
16 & 346 & 197 & 149 & 0.082 \\
\hline
\end{tabular}

